\title{
A STUDY OF HISTOPATHOLOGICAL CORRELATION WITH FINE NEEDLE ASPIRATION CYTOLOGY OF CERVICAL LYMPHADENOPATHY
}

\author{
Bobby Duarah', Asha Borah ${ }^{2}$ \\ ${ }^{1}$ Associate Professor, Department of Pathology, Assam Medical College, Dibrugarh. \\ ${ }^{2}$ Assistant Professor, Department of Pathology, Assam Medical College, Dibrugarh.
}

\section{ABSTRACT}

\section{BACKGROUND}

Cervical lymphadenopathy is a common manifestation in our country where incidence of tuberculosis and oral cancer is fairly high, so the proper and early diagnosis of lymphadenopathy is very important for early and effective treatment.

\section{AIM}

The present study was undertaken in the Department of Pathology, Assam Medical College and Hospital, for a period of one year with a view to correlate the cytological diagnosis with histopathology.

\section{MATERIALS AND METHODS}

A series of 100 cases with clinical presentation of palpable lymph node at any part of the cervical region irrespective of age and sex attending the different OPDs of this institution were taken. FNAC was done as an initial step for diagnosis. The results were confirmed by incisional/excisional biopsy afterwards.

\section{RESULT}

Out of 100 cases, there were 74 cases of benign lesions (74\%) and 26 cases of malignant lesions (26\%) proven histopathologically. The peak incidence of age group suffering from the disease was 21-30 years (25\%) followed by 11-20 years (24\%). Majority were Tubercular (40\%) followed by Inflammatory (34\%), Metastasis (16\%), and Lymphoma (10\%). All the cases (Benign and Malignant) presented with neck swelling (100\%). It was seen that the Jugulodigastric, Posterior triangle, and the submandibular groups of lymph nodes were the most commonly involved groups with a percentage being $41 \%, 21 \%$, and $13 \%$ respectively. Out of a total of 74 histologically proved benign cases, cytology could diagnose 73 cases (98.7\%). The percentage of accuracy was $98.7 \%$. Also, the cytological diagnosis could be obtained in 24 out of 26 cases with malignant lesions when correlated with histopathology. The percentage of accuracy was $92.3 \%$. It was seen that the overall accuracy rate of aspiration cytology in the diagnosis of benign lesions was $98.7 \%$ and that of malignant lesions was $92.3 \%$ against $100 \%$ accuracy with histopathology. The overall accuracy of aspiration cytology is $97 \%$.

\section{CONCLUSION}

Though histopathology gives the final definite diagnosis in most of the cases, it is hoped that the diagnostic error in fine needle aspiration cytology can be minimized to a negligible degree by acquiring skill and experience in performing the technique with thorough clinical knowledge and judgment.

\section{KEYWORDS}

Lymphadenopathy, FNAC, Metastatic Node.

HOW TO CITE THIS ARTICLE: Duarah B, Borah A. A study of histopathological correlation with fine needle aspiration cytology of cervical lymphadenopathy. J. Evolution Med. Dent. Sci. 2016;5(53):3486-3490, DOI: 10.14260/jemds/2016/805

\section{INTRODUCTION}

Disease conditions of the body are well reflected in the tissues and cells. Through them, a deep insight is gained in the processes of the body. Lymphadenopathy is a state of shift of normal cellular pattern due to such disease process. Apart from being involved in specific and nonspecific local inflammatory and systemic diseases, the cervical nodes can be affected in malignant lesions occurring in remote sites.

Financial or Other, Competing Interest: None.

Submission 13-05-2016, Peer Review 11-06-2016,

Acceptance 17-06-2016, Published 01-07-2016.

Corresponding Author:

Dr. Bobby Duarah,

Associate Professor

Department of Pathology,

$1^{\text {st }}$ Floor Basic Science Building,

Assam Medical College and Hospital,

Dibrugarh-786002, Assam.

E-mail: bobby.duarah@gmail.com

DOI: $10.14260 /$ jemds $/ 2016 / 805$
Therefore, the cervical lymph nodes form an important catchment area for the region of the head and neck, mediastinum, and other distant sites. Hence, the study of cervical lymph nodes is an intriguing and interesting subject in medical science.

Many a times, the clinicians are puzzled regarding the diagnosis of cervical lymphadenopathy and an unfortunate patient has to undergo a detailed investigative procedure, which is time consuming, traumatic, and expensive. Successful management demands a good clinical diagnosis supplemented by surgical biopsies and histopathological examination. Fine needle aspiration cytology has effectively bridged the gap between clinical diagnosis and tissue diagnosis.

In order to come to an accurate diagnosis of cervical lymphadenopathy, early planning and management and good prognosis, FNAC has an immense potential, which is cheap, less traumatic, simple, quick, and easy procedure. 


\section{MATERIALS AND METHODS}

The present study has been carried out in the Department of Pathology, Assam Medical College and Hospital, Dibrugarh, for a period of one year. A Series of 100 cases with clinical presentation of palpable lymph node at any part of the cervical region irrespective of age and sex attending the different OPDs of this institution were taken.

Every case taken up for the study was thoroughly examined including detailed history and clinical features and then they were subjected to various routine and special investigations prior to lymph node biopsy.

FNAC was done as an initial step for diagnosis. The results were confirmed by incisional/excisional biopsy afterwards. The material aspirated was made into smears. Smears were dried and others fixed in alcohol ether mixtures. The smears were then stained by conventional May-Grunwald-Giemsa stain, Papanicolaou stain, and Ziehl-Neelsen stain (Wherever required). Incisional/Excisional biopsy specimens were collected from operation theatre in $10 \%$ formalin solution. Slides were stained by Haematoxylin and Eosin stain.

\section{RESULT AND OBSERVATION}

The present study was carried out in the Department of Pathology, Assam Medical College and Hospital for a period of one year. A total number of 100 cases were selected randomly from the cases attending different OPDs with cervical lymphadenopathy as one of the presenting symptoms. These cases were studied, investigated, and analysed.

Out of 100 cases, there were 74 cases of benign lesions (74\%) and 26 cases of malignant lesions (26\%) proven histopathologically [Table I]. In the present study of benign lesions, 43 were males (58.11\%) and 31 were females (41.89\%). Among the malignant lesions, males were 22 $(84.62 \%)$ and females were $4(15.38 \%)$. The present study includes patients of all age groups. The peak incidence of age group suffering from the disease was 21-30 years (25\%) followed by 11-20 years (24\%). Majority of the benign lesions were in the age group 11-20 years and $21-30$ years $(28.38 \%$ each), whereas in the malignant lesions, the peak incidence occurred in the age group of $41-50$ years (46.15\%).

Out of a total of 100 cases, the majority were Tubercular (40\%) [Fig. I, Fig. II] followed by Inflammatory (34\%), Metastasis (16\%), and Lymphoma (10\%). All the cases (Benign and malignant) presented with neck swelling (100\%), the other clinical features were fever (41\%), cough (10\%), sore throat $(1 \%)$, neck pain $(10 \%)$, difficulty in swallowing (4\%), chest pain $(3 \%)$, respiratory distress $(1 \%)$, loss of weight (10\%), loss of appetite (8\%), discharging sinus (2\%), and haemoptysis (3\%).

On analysing the site of the palpable lymph nodes in all the different groups of the diseases, it was seen that the Jugulodigastric, Posterior triangle, and the submandibular groups of lymph nodes were the most commonly involved groups with a percentage being $41 \%, 21 \%$, and $13 \%$ respectively.

Of the 16 malignant lesions, primary sites were detected in 12 cases $(75 \%)$ and in 4 cases $(25 \%)$, the primary site could not be detected even after thorough investigation. Out of a total of 74 histologically proved benign cases, cytology could diagnose 73 cases (98.7\%). The present study shows majority of the cases with benign lesions were of tubercular origin, 40 cases $(54.05 \%)$, followed by chronic lymphadenitis 19 cases
(25.68\%), reactive lymphadenitis 12 cases (16.22\%), and acute lymphadenitis 3 cases (4.05\%).

Out of a total of 26 histologically proved malignant cases, cytology could diagnose 24 cases (92.3\%). Out of 26 malignant cases, secondary metastasis of squamous cell carcinoma show the highest number of cases, i.e. 11 cases (42.3\%) [Fig. III, Fig. IV] followed by Non-Hodgkin's Lymphoma 8 cases $(30.8 \%)$ [Fig. V, Fig. VI], Adenocarcinoma 5 cases (19.2\%), Hodgkin's Lymphoma 2 cases (7.7\%).

It was seen that cytological diagnosis could be obtained in 73 out of 74 cases, when correlated with histopathology. The percentage of accuracy was $98.7 \%$. Also, the cytological diagnosis could be obtained in 24 out of 26 cases with malignant lesions when correlated with histopathology. The percentage of accuracy was $92.3 \%$. It was seen that the overall accuracy rate of aspiration cytology in the diagnosis of benign lesions was $98.7 \%$ and that of malignant lesions was $92.3 \%$ against $100 \%$ accuracy with histopathology. The overall accuracy of aspiration cytology is $97 \%$. [Table II]. On analysing the overall accuracy rate, aspiration cytology showed a $97 \%$ accuracy rate as compared to clinical diagnosis of $90 \%$ against the final diagnosis by histopathology of $100 \%$.

\begin{tabular}{|c|c|c|}
\hline Type of Lesion & No. of Cases & Total (\%) \\
\hline Benign & 74 & $74 \%$ \\
\hline Malignant & 26 & $26 \%$ \\
\hline Total & $\mathbf{1 0 0}$ & $\mathbf{1 0 0 \%}$ \\
\hline \multicolumn{2}{|c|}{ Table I: Showing the Type of Lesion } \\
\hline
\end{tabular}

\begin{tabular}{|c|c|c|c|c|}
\hline \multirow{2}{*}{ Diagnosis } & \multicolumn{2}{|c|}{ Histology } & \multicolumn{2}{c|}{ Cytology } \\
\cline { 2 - 5 } & No. & $\%$ & No. & $\%$ \\
\hline Benign & 74 & 100 & 73 & 98.7 \\
Malignant & 26 & 100 & 24 & 92.3 \\
\hline Total & $\mathbf{1 0 0}$ & $\mathbf{1 0 0}$ & $\mathbf{9 7}$ & $\mathbf{9 7}$ \\
\hline Table II: Showing Comparison of Diagnostic Accuracy by \\
Histopathology and Cytology in Both Benign and \\
Malignant Lymphadenopathy \\
\hline
\end{tabular}

\begin{tabular}{|c|c|c|c|}
\hline Sl. No. & Studies & Year & Percentage \\
\hline 1 & Cathie & 1938 & $69 \%$ \\
\hline 2. & Bloch & 1967 & $89 \%$ \\
\hline 3. & Frable and Frable & 1974 & $91.98 \%$ \\
\hline 4. & Nazar Hussain et al & 2002 & $95 \%$ \\
\hline 5. & Present Study & 2006 & $97 \%$ \\
\hline \multicolumn{3}{|c|}{ Table III: Accuracy of FNAC in Various Studies } \\
\hline
\end{tabular}

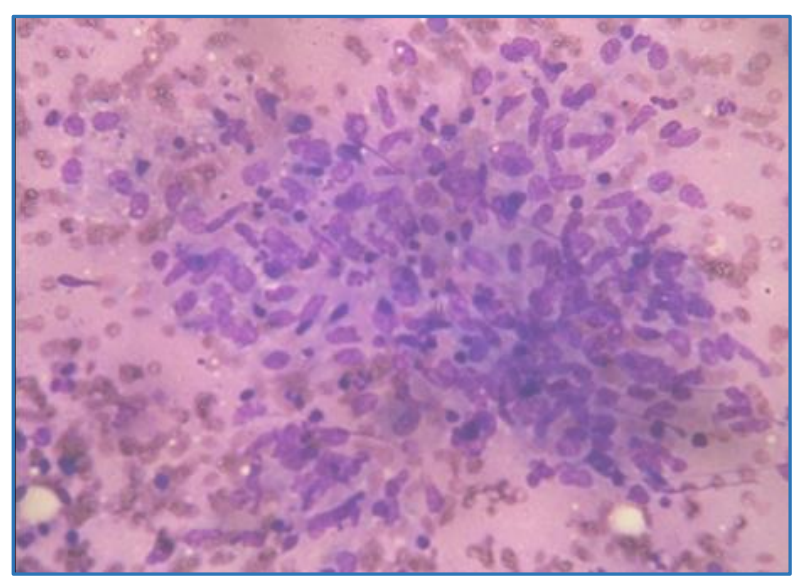

Fig. I: Photomicrographs Showing Aspiration Cytology of Epithelioid GRANULOMA in the Lymph Node (MGG) 


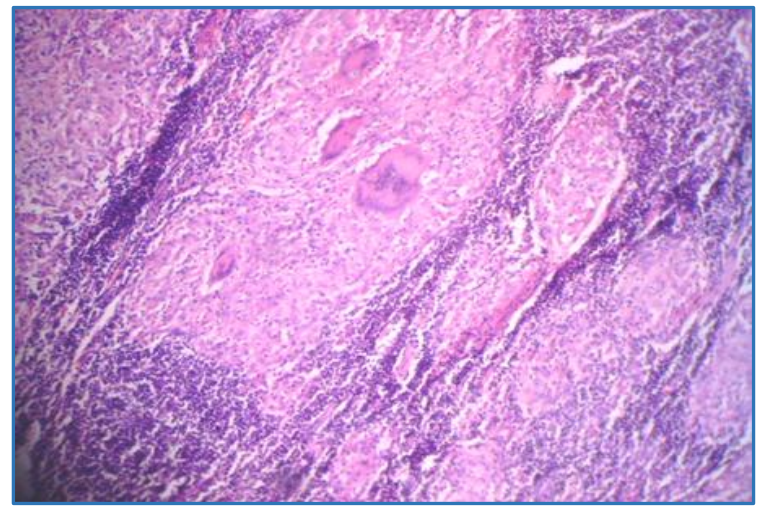

Fig. II: Photomicrograph Showing Histological Picture of Tubercular Granuloma in Lymph Node (H \& E)

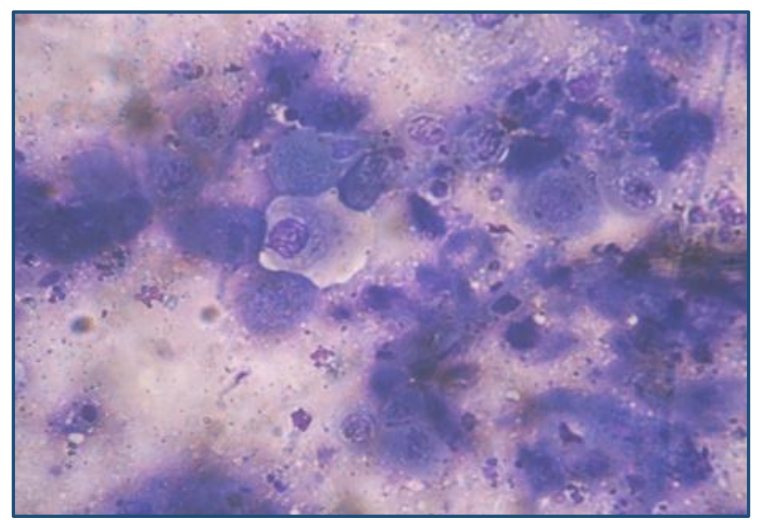

Fig. III: Photomicrograph of Aspiration Cytology Showing Groups of Malignant Squamous Cells Infiltrating the Lymph Node (MGG)

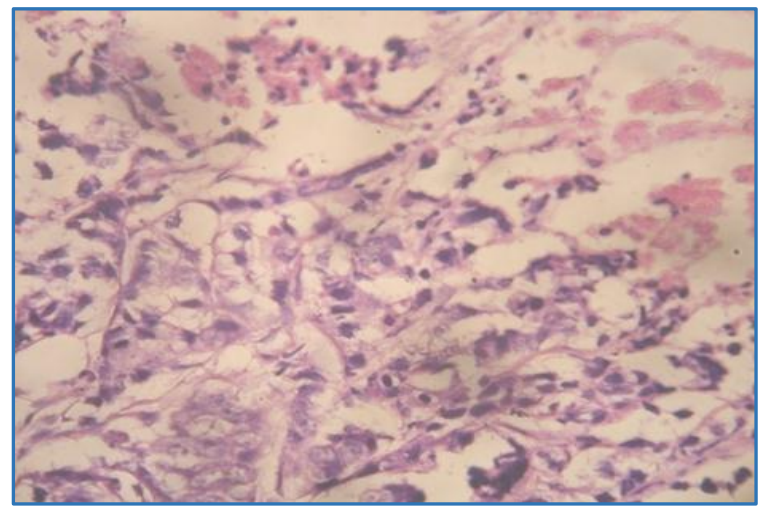

Fig. IV: Histological Picture Showing Infiltration of Squamous Cell Carcinoma into Lymph Node

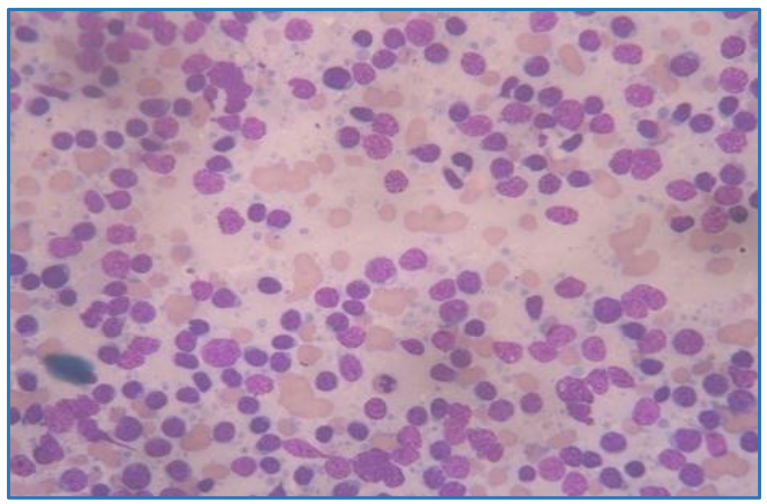

Fig. V: Photomicrograph of Aspiration Cytology Showing Non-Hodgkin's Lymphoma

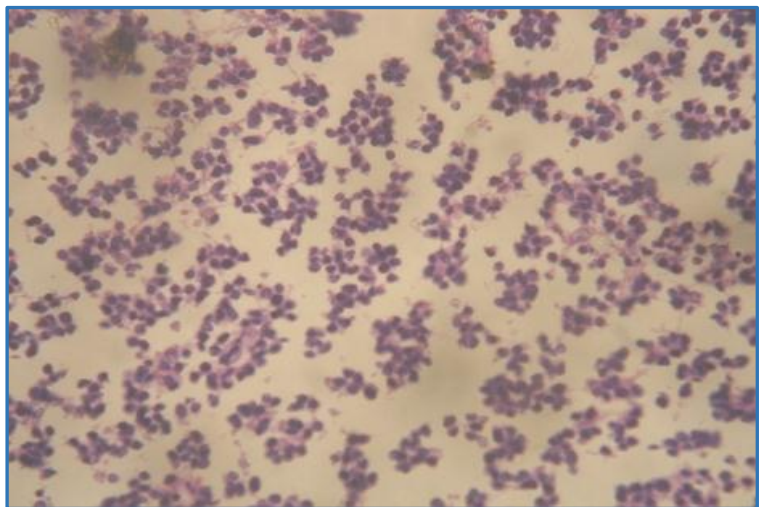

Fig. VI: Histological Picture Showing Non-Hodgkin's Lymphoma

\section{DISCUSSION}

The lymphatic system is one of the most important system of the body for it is through the lymphatic vessels that the bacterial infections passes from the exterior to interior of the body and it is through the same channels the agents of disease merge from one part of the body to another in infections, tuberculosis, and carcinoma.

In the present study, an attempt has been made to evaluate the suitability of FNAC. For the present study, 100 cases irrespective of age and sex were selected randomly. After thorough clinical examination and investigation, fine needle aspiration cytology and incision/excision biopsy were done.

Out of 100 cases studied, 40 cases (40\%) were tubercular in origin, 34 were inflammatory (34\%) in origin, metastasis 16 cases $(16 \%)$, lymphoma in 10 cases $(10 \%)$.

In the present study, the incidence of tuberculosis was similar to the findings of D. Malakar et al (1991) ${ }^{[1]}$ and M. Bajwa (2004).[2] The incidence of metastatic malignancy is lower due to increased public awareness and early treatment.

In the present study, maximum number of cases was seen in the age group 21-30 years (25\%) irrespective of benign and malignant conditions followed by 11-20 years age group (24\%).

Benign lesions were common in the age group 11-20 and 21-30 year (28.3\%) each. Malignant lesions were common in the age group $41-50$ years $(46.2 \%)$. These findings tally with the findings of Engell and Zejicek (1970) and Jahangir Sarwar Khan et al (2003). [3]

Sex distribution in the present study shows male preponderance over both benign and malignant lesions. Male and female percentage was $65 \%$ and $35 \%$ respectively. Male preponderance in both benign and malignant lesions coincides with the findings of Max Bloch (1967)[4] and Faisal Ghani Siddique et al (2002). [5]

In the present study, 34 cases (34\%) were found to be inflammatory in origin. Of the 34 cases, 3 cases were acute lymphadenitis, 19 cases were chronic lymphadenitis, and 12 cases were reactive lymphadenitis.

Reactive lymphadenitis was found in 12 cases in the present study on histological examination, but aspiration cytology diagnosed 14 cases as reactive lymphadenitis. So, false positive was seen in 2 cases. Histological examination of the two cases was found to be Non-Hodgkin's Lymphoma.

Chronic lymphadenopathy was found in 19 cases on histological examination, but aspiration cytology diagnosed 20 cases as chronic lymphadenitis. So, false positive was seen in 1 case. Histological examination of the case showed to be 
tubercular lymphadenitis. False positive was obtained in 2 cases of reactive lymphadenitis, 1 case of chronic lymphadenitis. The false positive results were probably due to improper site of aspiration and scanty material on aspiration.

In this series, cytology offered an accuracy of $100 \%$ correlating histopathology, which is higher than Lucas (1955).[6]

In the present study, 40 cases were found tubercular in origin (40\%).

Majority of the cases were in the age group 11-20 years. The youngest one was 2 years old and the oldest was 65 years old. Jugulodigastric node was most commonly affected and found in 15 cases (15\%). The most common symptom was neck swelling and fever. These finding are similar to the previous workers.

Out of the total 40 histologically-proved cases, aspiration cytology was correct in only 39 cases of tubercular lymphadenopathy. So, false negative by aspiration cytology in the diagnosis of tubercular lymphadenopathy in this study was 1. The percentage of accuracy was 97.5. Accuracy rate of other workers was Lucas (1955) 16\%, Max Bloch (1967) 80\%. The higher accuracy in the present study is due to the improvement in technique of aspiration. The one false negative case in cytology was shown as chronic lymphadenitis. The false negative is perhaps due to scanty material on aspirate.

Out of 10 cases diagnosed as lymphoma, 2 cases were diagnosed as Hodgkin's lymphoma and 8 cases as nonHodgkin's lymphoma with a percentage being $2 \%$ and $8 \%$ respectively. The youngest patient of Hodgkin's lymphoma was 14 year old male and oldest was 16 year old female. The nodes of the posterior triangle was commonly involved. The most common presenting symptom was painless neck swelling. These findings were similar to the previous workers. Of the 2 histologically proved Hodgkin's lymphoma, aspiration cytology could diagnose both of them with an accuracy of $100 \%$. Accuracy rate of other workers are Morrison et al (1952) 83\%,[7] Max Bloch (1967) 80\%, Friedman et al (1980) 90.1\%. 100\% accuracy in FNAC in this study is perhaps due to less number of patients with Hodgkin's lymphoma (only 2 cases), improvement in staining technique and better interpretation. Lymph node biopsy helped in histological typing in addition to confirmation of diagnosis. Both the cases were lymphocyte depleted type of Hodgkin's lymphoma.

The youngest case of non-Hodgkin's lymphoma was 31/2 year old male and oldest case 55 year old male. The nodes of the posterior triangle were commonly involved. Most common presenting symptom was painless neck swelling. These findings were similar to those of previous workers. Of the 8 histologically-proved cases, aspiration cytology diagnosed only 6 cases with percentage being 75\%. Two cases were shown to be as reactive lymphadenitis by FNAC. The accuracy rate of other workers were Morrison (1952) 80\% and Max Bloch (1967) 80\%. The accuracy rate of present study is lower as compared to other workers perhaps due to inadequate smear, scanty cellularity, and less number cases of NHL in the study. Histological examination showed 2 cases of small cell type of NHL, 5 cases of small and large cell type of NHL, and 1 case of follicular lymphoma.
In the present study, metastatic malignancy was found in 16 cases (16\%). Of the 16 cases, 11 were metastatic squamous cell carcinomas and 5 were metastatic adenocarcinomas. Of the metastatic adenocarcinoma cases, 2 cases were from the thyroid, 1 from stomach, 2 from gallbladder. Of the 11 metastatic squamous carcinoma in 7 cases, primary lesions were found in Nasopharynx, Oropharynx, Hypopharynx, and Larynx. In the rest 4 cases, primary lesions were not found even after thorough investigation.

The accuracy rate of FNAC was $100 \%$. The accuracy rate of other workers were Morrison et al (1952) 100\%, Max Bloch (1967) 87\%, Frable and Frable (1974) 96.8\% [8], Kline et al (1983) 95\%.[9]

In the present study of 100 cases of cervical lymphadenopathy ( 74 histologically proven benign and 26 histologically proven malignant), aspiration cytology showed a high accuracy rate of $97 \%$ as compared to clinical diagnosis of $90 \%$ against the final diagnosis by histopathology of $100 \%$.

Cytology in the present study offered a high rate of success than Cathie (1938), Bloch (1967), Frable and Frable (1974), Nazar Hussain et al (2002) [10] [Table III]. Accuracy of diagnosis by aspiration cytology depends on several factors like adequate material, good staining, and experienced cytologist. The cause of unsatisfactory result in some of the cases may be due to (1) faulty technique (2) improper staining and (3) scanty cellularity.

\section{CONCLUSION}

Fine Needle Aspiration Cytology is rapid simple, safe, painless, and cost-effective procedure of diagnosis with minimal deleterious effects. Hospitalization of the patient is not necessary and can be performed in an outpatient department or bedside procedure in a busy hospital like ours.

The accuracy rate of cytology for benign group was $98.7 \%$ and for malignant group 92.3\%. Overall accuracy rate of FNAC was $97 \%$ against cent percent accuracy by histology.

Considering the merits and demerits of fine needle aspiration cytology as compared to the excision biopsy, it can be said that the former has a definite edge over the latter. However, excision biopsy gives the final definite diagnosis in most of the cases.

\section{REFERENCES}

1. Malakar D, Jajoo ILN, Swarup K, et al. A clinical evaluation of fine needle aspiration cytology in the diagnosis of lymphadenopathy. Ind J Tub 1991;38:17-19.

2. Bajwa M. Cervical lymphadenopathy PIMS experience. J Rawal Med Coll 2004;8(2):78-82.

3. Khan JS, Latif Z, Hasan H, et al. Tuberculous lymphadenitis as a cause of cervical lymphadenopathy. J Rawal Med Coll 2003;7(1):36-8.

4. Bloch M. Comparative study of lymph node cytology by puncture and histopathology. Acta Cytol 1967;11(2): 139-44.

5. Siddiqui FG, Ahmed Q. Cervical lymphadenopathy. J Surg Pakistan 2002;7(3):23-5.

6. Lucas PF. Lymph node smears in the diagnosis of lymphadenopathy: a review. Blood 1955;10(10): 1030-54. 
7. Morrison M, Samwick AA, Rubinstein J, et al. Lymph node aspiration clinical and haematologic observations in 101 patients. Am J Clin Pathol 1952;22(3):255-62.

8. Frable WJ, Frable MA. Thin needle aspiration biopsy in the diagnosis of head and neck tumours. The Laryngoscope 1974;84(7):1069-77.
9. Kline TA, Neal HS, Holroyde CP. Needle aspiration biopsy diagnosis of subcutaneous nodule and lymph nodes. JAMA 1976;235(26):2848-50.

10. Hussain N, Sheikh AS, Bokhari MH. The value of fine needle aspiration cytology in the diagnosis of lymphadenopathy. Biomedica 2002;18:38-40. 